Emmanouil Rampakakis: None declared, Angela Cesta: None declared, John Sampalis: None declared, Claire Bombardier Grant/research support from: Dr Bombardier reports sources of funding for Ontario Best Practice Research Initiative Research grants from Abbvie, Janssen, Amgen, Medexus, Merck, Pfizer, and Novartis outside of the submitted work. Consulting Agreements: Abbvie, Covance, Janssen, Merck, Pfizer, Sanofi and Novartis outside of the submitted work. Advisory Board Membership: Hospira, Sandoz, Merck, Pfizer and Novartis outside of the submitted work.

DOI: 10.1136/annrheumdis-2020-eular.1751

\section{SAT0050 PREDICTION OF RESPONSE TO CERTOLIZUMAB PEGOL TREATMENT BY FUNCTIONAL MRI OF THE BRAIN: AN INTERNATIONAL, MULTI-CENTER, RANDOMIZED, DOUBLE-BLIND, PLACEBO- CONTROLLED TRIAL (PRECEPRA)}

J. Rech ${ }^{1}$, K. Tascilar ${ }^{1}$, H. Schenker ${ }^{1}$, M. Sergeeva ${ }^{2}$, M. Selvakumar ${ }^{2}$, L. Konerth², J. Prade' ${ }^{2}$, S. Strobelt' ${ }^{2}$, M. Hagen ${ }^{1}$, V. Schönau', L. Valor ${ }^{1}$, A. Hueber ${ }^{3}$, D. Simon ${ }^{1}$, A. Kleyer ${ }^{1}$, F. Behrens ${ }^{4}$, J. A. P. Da Silva ${ }^{5}$, C. Baerwald ${ }^{6}$, S. Finzel ${ }^{7}$, R. Voll ${ }^{7}$, E. Feist $^{8,9}$, A. Doerfler ${ }^{10}$, N. Damjanov ${ }^{11}$, A. Hess ${ }^{2}$, G. Schett ${ }^{1}{ }^{1}$ Friedrich-Alexander University (FAU) Erlangen-Nürnberg and Universitätsklinikum Erlangen, Department of Internal Medicine 3 Rheumatology and Immunology, Erlangen, Germany; ${ }^{2}$ Friedrich-Alexander University (FAU) Erlangen-Nürnberg, Institute for Experimental Pharmacology, Erlangen, Germany; ${ }^{3}$ Sozialstiftung Bamberg, Section Rheumatology, Bamberg, Germany; ${ }^{4}$ Goethe University Frankfurt, Rheumatology and Fraunhofer TMP, Frankfurt am Main, Germany; ${ }^{5}$ Hospitais da Universidade (SRHUC), Department Reumatologia, Coimbra, Portugal; ${ }^{6}$ Universität Leipzig, Medizinische Klinik III - Bereich Rheumatologie, Leipzig, Germany; ${ }^{7}$ Universitätsklinikum Freiburg, Klinik für Rheumatologie und Klinische Immunologie, Freiburg, Germany; ${ }^{8}$ Klinik für Rheumatologie der Helios Fachklinik, Vogelsang-Gommern, Germany; ${ }^{9}$ Charité - Universitätsmedizin Berlin, Dpt. of Rheumatology and Clinical Immunology, Berlin, Germany; ${ }^{10}$ Friedrich-Alexander University (FAU) Erlangen-Nürnberg and Universitätsklinikum Erlangen, Abteilung für Neuroradiologie, Erlangen, Germany; ${ }^{11}$ Belgrade University School of Medicine, Institute of Rheumatology, Belgrade, Serbia

Background: Personalization of RA treatment is not optimal due to lack of predictors. We previously demonstrated in RA patients that central nervous system (CNS) pain response to tender joint compression, measured by using functional MRI (fMRI) of the brain rapidly wanes after 24 hours of anti-TNF administration and that a higher pre-treatment BOLD signal volume seems to predict clinical response to treatment with certolizumab-pegol $(C Z P)^{1,2}$. We therefore hypothesized that the CNS pain response upon compression of a painful joint could predict subsequent anti-TNF treatment response.

Objectives: To compare disease activity after 12-weeks of CZP treatment to that of placebo in DMARD-refractory RA patients based on pre-treatment baseline CNS pain response measured using BOLD fMRI.

Methods: Adult RA patients fulfilling the 2010 ACR/EULAR classification criteria with a DAS28>3.2 under stable DMARD treatment for at least 3 months were eligible. Patients underwent $\mathrm{fMRI}$ scanning of the brain at screening for stratification by CNS pain response. Whole brain BOLD-signal-voxel-count of 700 units classifying between low and high, and were randomized to CZP or placebo (2:1) The primary outcome was low disease activity (LDA, DAS28 $\leq 3.2)$ after 12 weeks of treatment.

Results: 156 RA patients, inadequate responders to csDMARD, signed the informed consent. 139 patients (46/47, 46/49 and 42/43) (99 females, 71\%) with moderate-high disease activity (mean (SD) DAS-28: 4.83 (1.03)) could be included respectively and completed the 12-week study treatment. Geometric mean (SD) numbers of baseline BOLD signal positive voxels were 559 (10), 81 (12) and 2498 (3) in the 3 arms respectively. The mean DAS28 (SD) scores after 12 weeks of study treatment were Placebo: 3.89 (1.29), CZP-L: 3.42 (1.06) and CZP-H: 3.06 (1.04). LDA was achieved in $12 / 47$ patients $(25.5 \%)$ in placebo, $22 / 49(44.9 \%)$ in the CZP$\mathrm{L}$, and $25 / 43,(58.1 \%)$ in the CZP-H arm. The linear effect term for the ordinal study group variable supported a linear trend of increasing CZP treatment effect with increasing baseline CNS pain response. RR $(95 \% \mathrm{Cl})$ for achieving LDA with each unit increase in treatment category over placebo was 1.79 (1.24 to 2.74, $p=0.003$ ).

Conclusion: A higher pre-treatment brain activity in response to pain measured with $\mathrm{MMRI}$ predicts the chance of achieving low disease activity with CZP treatment.

References:

[1] Hess, A. et al. PNAS (2011)

[2] Rech, J. et al. Arthritis \& Rheumatism (2013).

\begin{tabular}{|c|c|c|c|c|c|}
\hline & & \multirow[t]{2}{*}{ Overall } & \multicolumn{3}{|c|}{ Study group } \\
\hline & & & Centolixumab-Mil & Certolizumab-Lc & Placebo \\
\hline & & 139 & 43 & 49 & 47 \\
\hline \multicolumn{2}{|c|}{ mean $(S D)$} & $543(11.8)$ & $54.3(10.8)$ & $565(12.2)$ & $52.1(12.0)$ \\
\hline \multirow[t]{2}{*}{1} & Female & $99(71.2)$ & $34(79.1)$ & $35(71.4)$ & $30(638)$ \\
\hline & Male & $40(28.8)$ & $9(20.9)$ & $14(28.6)$ & $17(36.2)$ \\
\hline \multirow[t]{2}{*}{ in, years } & Mean(SD) & $6.2(8.1)$ & $6.0(8.3)$ & $6.4(8.6)$ & $6.2(7.6)$ \\
\hline & Median(IQR) & $2.0(1.0-8.9$ & $2.0(1.0-9.0)$ & $30(10-8.0)$ & $30(1.0-8.0)$ \\
\hline \multirow[t]{4}{*}{ 6) } & Negative & $34(24.5)$ & $15(34.9)$ & $9(184)$ & $10(21.3)$ \\
\hline & Positive & $105(75.5$ & $28(65.1)$ & $40(81.6)$ & $37(78.7)$ \\
\hline & Negative & $39(28.1)$ & $12(27.9)$ & $13(26.5)$ & $14(298)$ \\
\hline & Positive & $100(71.9$ & $31(72.1)$ & 36 (73.5) & $33(70.2)$ \\
\hline \multicolumn{2}{|c|}{ nts (28), mean (SD) } & 10.2(6.5: & $9.3(6.4)$ & $11.3(6.7)$ & $9.9(6.2)$ \\
\hline \multicolumn{2}{|c|}{ ints (28), mean (SD) } & $7.9(5.3)$ & $7.0(4.4)$ & $87(6.3)$ & $8.0(4.8)$ \\
\hline \multicolumn{2}{|c|}{ bal VAS, mm, mean (SD) } & $58.0(2000$ & $57.2(19.9)$ & $59.1(17.8)$ & $57.6(22.5)$ \\
\hline \multicolumn{2}{|c|}{ global VAS, mm, mean (SD) } & $49.6(18.7$ & $46.0(20.2)$ & $495(19.2)$ & $53.1(16.2)$ \\
\hline \multicolumn{2}{|c|}{$n m$, mean (SD) } & $55.2(193$ & $53.5(18.0)$ & $57.1(17.0)$ & $54.9(22.7)$ \\
\hline \multicolumn{2}{|c|}{ A, mean (SD) } & $25.8(19.9$ & $23.7(19.0)$ & $25.2(17.1)$ & $28.2(23.2)$ \\
\hline \multicolumn{2}{|c|}{, mean (SD) } & $8.7(13.0)$ & $6.8(12.7)$ & $7.9(8.7)$ & $11.2(16.5)$ \\
\hline \multicolumn{2}{|c|}{$\mathrm{y} / \mathrm{h}$ mean (SD) } & $4.8(1.0)$ & $4.7(1.0)$ & $5.0(1.1)$ & $4.9(1.0)$ \\
\hline
\end{tabular}

mocyte sedimentation rate; CRP. Creactive protein; DAS.28, disease activity score 28 foints

Acknowledgments : The study was supported by an unrestricted grant from UCB Biopharma SPRL, Brussels, Belgium

Disclosure of Interests: Jürgen Rech Consultant of: BMS, Celgene, Novartis, Roche, Chugai, Speakers bureau: AbbVie, Biogen, BMS, Celgene, MSD, Novartis, Roche, Chugai, Pfizer, Lilly, Koray Tascilar: None declared, Hannah Schenker: None declared, Marina Sergeeva: None declared, Mageshwar Selvakumar: None declared, Laura Konerth: None declared, Jutta Prade: None declared, Sandra Strobelt: None declared, Melanie Hagen: None declared, Verena Schönau: None declared, Larissa Valor: None declared, Axel Hueber Grant/research support from: Novartis, Lilly, Pfizer, EIT Health, EU-IMI, DFG, Universität Erlangen (EFI), Consultant of: Abbvie, BMS, Celgene, Gilead, GSK, Lilly, Novartis, Speakers bureau: GSK, Lilly, Novartis, David Simon Grant/research support from: Else Kröner-Memorial Scholarship, Novartis, Consultant of: Novartis, Lilly, Arnd Kleyer Consultant of: Lilly, Gilead, Novartis,Abbvie, Speakers bureau: Novartis, Lilly, Frank Behrens Grant/research support from: Abbvie, Pfizer, Roche, Chugai, Janssen, Consultant of: Abbvie, Pfizer, Roche, Chugai, UCB, BMS, Celgene, MSD, Novartis, Biotest, Janssen, Genzyme, Lilly; Boehringer; Sandoz, Speakers bureau: Abbvie, Pfizer, Roche, Chugai, UCB, BMS, Celgene, MSD, Novartis, Biotest, Janssen, Genzyme, Lilly; Boehringer; Sandoz, José Antonio P. da Silva Grant/research support from: Pfizer, Abbvie, Consultant of: Pfizer, AbbVie, Roche, Lilly, Novartis, Christoph Baerwald Consultant of: CGB received speaker or consulting fees from AbbVie, Paid instructor for: CGB received speaker or consulting fees from AbbVie, Speakers bureau: CGB received speaker or consulting fees from AbbVie, Stephanie Finzel: None declared, Reinhard Voll: None declared, Eugen Feist Consultant of: Novartis, Roche, Sobi, Lilly, Pfizer, Abbvie, BMS, MSD, Sanofi, Speakers bureau: Novartis, Roche, Sobi, Lilly, Pfizer, Abbvie, BMS, MSD, Sanofi, Arnd Doerfler: None declared, Nemanja Damjanov Grant/ research support from: from AbbVie, Pfizer, and Roche, Consultant of: AbbVie, Gedeon Richter, Merck, Novartis, Pfizer, and Roche, Speakers bureau: AbbVie, Gedeon Richter, Merck, Novartis, Pfizer, and Roche, Andreas Hess: None declared, Georg Schett Speakers bureau: AbbVie, BMS, Celgene, Janssen, Eli Lilly, Novartis, Roche and UCB

DOI: 10.1136/annrheumdis-2020-eular.4288

\section{SAT0051 REMISSION IN RHEUMATOID ARTHRITIS PATIENTS: A CLUSTER ANALYSIS TO IDENTIFY AND CHARACTERIZE SUBPOPULATIONS OF PATIENTS}

A. Madrid García ${ }^{1}$, D. Freites Nuñez ${ }^{2}$, J. Font ${ }^{3}$, I. Hernandez ${ }^{3}$, L. León ${ }^{2}$, J. I. Colomer ${ }^{2}$, I. González-Álvaro ${ }^{4}$, B. Fernandez ${ }^{3}$, J. A. Jover ${ }^{3}$, L. Abasolo ${ }^{2}$, L. Rodriguez Rodriguez ${ }^{2} .^{1}$ Fundación para la Investigación BiomedicaHCSC, Madrid, Spain; ${ }^{2}$ Fundación para la Investigación Biomedica - HCSC, Rheumatology, Madrid, Spain; ${ }^{3}$ Hospital Clínico San Carlos, Rheumatology, Madrid, Spain; ${ }^{4}$ Hospital Universitario La Princesa, Madrid, Spain

Background: Disease Activity Score (DAS) is a continuous measure of Rheumatoid Arthritis (RA) activity, used in clinical practice for monitoring disease progression and for documenting treatment response. According to EULAR, the clinical desired target is to achieve a remission state (or failing that, low disease activity). However, the population of RA patients in this state could be heterogenous. 
Objectives: To characterize the level of heterogeneity of RA patients in remission by identifying clusters based on the DAS28 components; and to describe inter and intra-class cluster demographic and clinical characteristics

Methods: Patients from Hospital Clínico San Carlos cohort, stored in a departmental electronic health record from January $1^{\text {st }}, 2000$ to December $30^{\text {th }}$, 2018, diagnose with RA according ACR 1986/ 2010 criteria were eligible for this study. Only observations with a DAS28 Erythrocyte Sedimentation Rate (ESR) value < 2.6 value were considered. ESR, patient's Global Health $(\mathrm{GH})$, and tender and swollen joints were used for calculating the clusters. Different aggregation levels for joints were studied as well as the input variable types. Isolated joints, joints grouped by the type of affectation (swollen or tender) or anatomic location or laterality aggregation levels were considered. Variables expressed as present or absent (i.e. dichotomous), continuous (count of joins) and categorical (type of joints) were also studied. Gower's distance, used for dealing with variables of different type, was employed to calculate the distance matrix. The number of suitable clusters was chosen from two to seven clusters based on the width value of a Silhouette analyses. Finally, Partitioning Around Medoids (PAM) was used as the clustering algorithm. Differences among clusters regarding demographic and clinical characteristics were analyzed using t-student chi2 test.

Results: 812 patients with 1,431 observations were analyzed in this study. The joint aggregation level which showed a highest Silhouette width value (0.708) was the anatomic one. In this aggregation level, five dichotomous variables (presence of tenderness and/or swelling in right and/or left shoulder, elbow, wrist, knee and hand (including both metacarpophalangeal and proximal interphalangeal joints) and two continuous variables (ESR and $\mathrm{GH}$ ) were used. Two clusters were found: the cluster A) with 1,305 observations and 742 patients and the B) with 126 observations and 115 patients. Cluster b) had a statistically significant higher DAS28-ESR value (higher number of tender and swollen joints, and higher $\mathrm{GH}$, but lower ESR), longer follow-up time (6.5 vs. 4.7 years), higher VAS-pain score (10 vs. 2 ), and higher HAQ score ( 0.25 vs. 0.12$)$. In addition, the proportion of patients treated with oral corticosteroids (63\% s. $50 \%)$ and biological therapy $(29 \%$ vs. $12 \%$ ) was higher.

Conclusion: We have identified two clinically distinct populations of RA patients in remission according to DAS28-ESR $<2.6$. Each subgroup could be associated with different outcomes during follow-up, such as radiographic progression or risk of relapse.

Disclosure of Interests: Alfredo Madrid García: None declared, Dalifer Freites Nuñez: None declared, Judit Font: None declared, Isabel Hernandez: None declared, Leticia León: None declared, Jose Ignacio Colomer: None declared, Isidoro González-Álvaro Grant/research support from: Roche Laboratories, Consultant of: Lilly, Sanofi, Paid instructor for: Lilly, Speakers bureau: Abbvie, MSD, Roche, Lilly, Benjamin Fernandez: None declared, J Angel Jover: None declared, Lydia Abasolo: None declared, Luis Rodriguez Rodriguez: None declared

DOI: 10.1136/annrheumdis-2020-eular.5750

\section{SAT0052 THERAPEUTIC STRATEGIES IN DIFFICULT-TO- TREAT RHEUMATOID ARTHRITIS: PRELIMINARY RESULTS OF A SYSTEMATIC LITERATURE REVIEW INFORMING THE 2020 EULAR RECOMMENDATIONS FOR THE MANAGEMENT OF DIFFICULT-TO-TREAT RHEUMATOID ARTHRITIS}

N. M. T. Roodenrijs ${ }^{1}$, A. Hamar ${ }^{2}$, M. Kedves ${ }^{3}$, G. Nagy ${ }^{4}$, J. M. Van Laar ${ }^{1}$, D. Van der Heijde ${ }^{5}$, P. Welsing ${ }^{1}{ }^{1}$ University Medical Center Utrecht, Department of Rheumatology \& Clinical Immunology, Utrecht, Netherlands; ${ }^{2}$ University of Debrecen, Department of Rheumatology, Debrecen, Hungary; ${ }^{3}$ BácsKiskun County Hospital, Department of Rheumatology, Kecskemét, Hungary; ${ }^{4}$ Semmelweis University, Department of Genetics, Cell- and Immunobiology \& Department of Rheumatology, 3rd Department of Internal Medicine, Budapest, Hungary; ${ }^{5}$ Leiden University Medical Center, Department of Rheumatology, Leiden, Netherlands

Background: Rheumatoid arthritis (RA) patients treated according to European League Against Rheumatism (EULAR) recommendations failing $\geq 2$ biological or targeted synthetic disease-modifying antirheumatic drugs (b/tsDMARDs) with a different mode of action who still have complaints which may be suggestive of active disease may be defined as suffering from 'difficult-to-treat RA' Management recommendations for RA focus predominantly on the earlier phases of the disease and specific recommendations for difficult-to-treat RA patients are currently lacking. ${ }^{1}$

Objectives: To systematically summarise evidence in the literature on pharmacological and non-pharmacological therapeutic strategies for difficult-to-treat RA patients, informing the 2020 EULAR recommendations for the management of difficult-to-treat RA.

Methods: A systematic literature review (SLR) was performed: PubMed, Embase and Cochrane databases were searched up to December 2019. Relevant papers were selected and appraised.

Results: Thirty articles were selected for therapeutic strategies in patients with limited DMARD options due to contraindications, 73 for patients in whom previous b/tsDMARDs were not effective ('true refractory RA'), and 51 for patients with predominantly non-inflammatory complaints. For patients with limited DMARD options, limited evidence was found on effective DMARD options for patients with concomitant obesity, and on safe DMARD options for patients with concomitant hepatitis B and C. In patients who failed $\geq 2$ bDMARDs, tocilizumab, tofacitinib, baricitinib, upadacitinib and filgotinib were found to be more effective than placebo, but evidence was insufficient to prioritise. In patients who failed $\geq 1$ bDMARD, there was a tendency of non-tumour necrosis factor inhibitor (TNFi) bDMARDs to be more effective than TNFi (Figure 1). Generally, b/tsDMARDs become less effective when patients failed more bDMARDs, this tendency was not clear for upadacitinib and filgotinib (Figure 2). In patients with predominantly non-inflammatory complaints (mainly function, pain and fatigue), exercise, education, psychological and self-management interventions were found to be of additional benefit.

Conclusion: This SLR underscores the scarcity of evidence on the optimal treatment of difficult-to-treat RA patients. As difficult-to-treat RA is a newly defined disease state, all evidence is to an extent indirect. Several b/tsDMARDs were found to be effective in patients who failed $\geq 2$ bDMARDs and generally effectiveness decreased with a higher number of failed bDMARDs. Additionally, a beneficial effect of non-pharmacological interventions was found on non-inflammatory complaints.
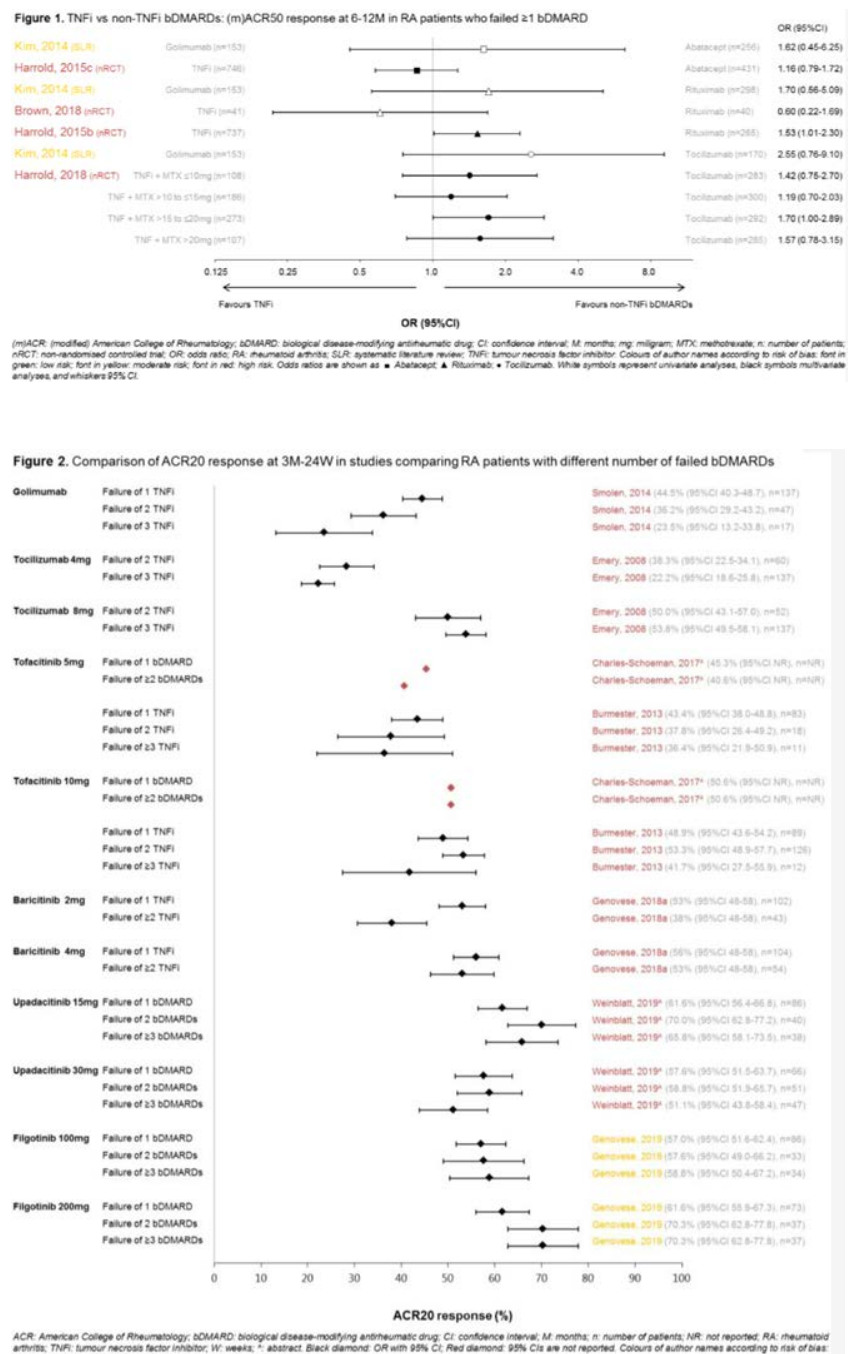